\title{
Hemorrhagic Ulcers after Great East Japan Earthquake and Tsunami: Features of Post-Disaster Hemorrhagic Ulcers
}

\author{
Takeshi Kanno $^{a}$ Katsunori lijima ${ }^{a}$ Yasuhiko Abe $^{a}$ Tomoyuki Koike ${ }^{a}$ \\ Norihiro Shimada ${ }^{b}$ Tatsuya Hoshic Nozomu Sano ${ }^{d}$ Motoki Ohyauchi ${ }^{\mathrm{e}}$

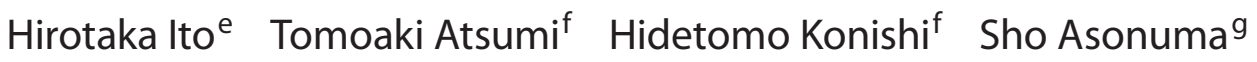 \\ Tooru Shimosegawa ${ }^{a}$
}

${ }^{a}$ Division of Gastroenterology, Tohoku University Graduate School of Medicine, Sendai, ${ }^{b}$ Department of Gastroenterology, Red Cross Ishinomaki Hospital, Ishinomaki, 'Department of Gastroenterology, Kesennuma City Hospital, Kesennuma, d Department of Gastroenterology, Shiogama City Hospital, Shiogama, e Department of Gastroenterology, Osaki Citizen Hospital, Osaki, ${ }^{\mathrm{f} D e p a r t m e n t}$ of Gastroenterology, Kurihara Central Hospital, Kurihara, and ${ }^{9}$ Department of Gastroenterology, South Miyagi Medical Center, Ogawara, Japan

\section{Key Words}

Hemorrhagic ulcer • Great earthquake - Endoscopic hemostasis

\begin{abstract}
Background: We investigated the characteristic features and treatment of hemorrhagic peptic ulcers after the Great East Japan Earthquake, which occurred on 11 March 2011. Methods: Clinical data of patients with hemorrhagic peptic ulcers were retrospectively collected during the 3 months after the earthquake from seven major hospitals in the middle of the stricken area, and were compared with those during the same period of the previous year. Results: After the earthquake, the number of hemorrhagic ulcers increased 2.2 fold as compared with the previous year, and gastric ulcers were significantly more frequent compared with duodenal ulcers $(p<0.05)$ and more often presented multiple forms $(p<0.05)$. Nonetheless, the proportion of re-bleeding cases
\end{abstract}

\section{KARGER}

Fax +4161306 1234

E-Mail karger@karger.ch

www.karger.com (c) 2013 S. Karger AG, Basel

$0012-2823 / 13 / 0871-0040 \$ 38.00 / 0$

Accessible online at:

www.karger.com/dig after hemostasis treatment ( $8 \%$ in 2010 vs. $5 \%$ in 2011) or total mortality rate ( $2.5 \%$ in 2010 vs. $1.2 \%$ in 2011$)$ was rather lower after the earthquake compared with that of the previous year. Conclusion: We clarified that post-disaster hemorrhagic ulcers existed frequently in the stomach, often as multiple ulcers at the same time. The Great East Japan Earthquake and Tsunami caused many cases of hemorrhagic ulcer. However, because of the high success rate of endoscopic hemostasis, the mortality remained as low as in the previous year. Our present study provides important information for large-scale disasters which can occur anywhere.

Copyright $\odot 2013$ S. Karger AG, Basel

\section{Introduction}

The Great East Japan Earthquake was a magnitude 9.0 undersea megathrust earthquake off the coast of Japan that occurred at 14:46 on 11 March 2011. It was the most 


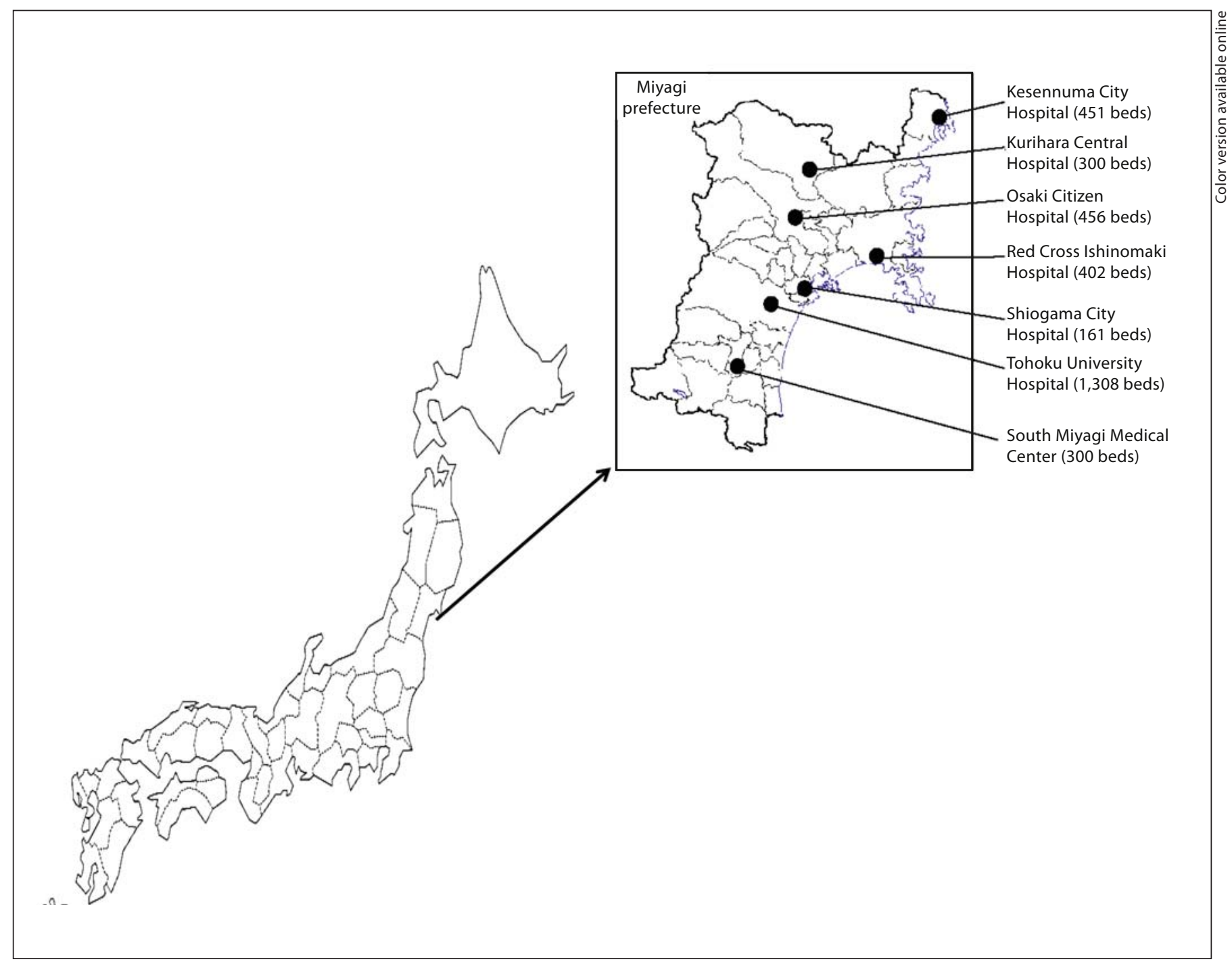

Fig. 1. Location of Miyagi prefecture in Japan and the participating hospitals of this survey.

powerful earthquake ever known to have hit Japan, and one of the five most powerful earthquakes in the world since modern record keeping began in 1900 . The tsunami that followed the earthquake swallowed up towns along the Pacific coastal area of Tohoku and Kanto district. The number of evacuees was around 400,000 people. On 12 March 2012, a Japanese National Police Agency report confirmed over 15,000 deaths and over 3,000 people missing across twenty prefectures.

Miyagi prefecture is located in the middle of the stricken area, and the whole area was severely damaged, especially the coastal area due to the tsunami. Immediately after the earthquake we noticed a dramatic increase in the occurrence of peptic ulcers, especially hemorrhagic ones, as also occurred after the Hanshin-Awaji Earthquake in 1995 [1].

In this study, in order to determine the features of post-disaster hemorrhagic ulcers, we retrospectively collected the clinical data from the 3 months after the earthquake from seven major hospitals in Miyagi prefecture, and then compared them with those collected during the same period of the previous year. We paid special attention to the features of hemorrhagic ulcer diseases after the earthquake and the subsequent treatment of these patients. 
Table 1. Comparison of patients after the earthquake in 2011 with those seen in 2010: background of patients with hemorrhagic ulcers

\begin{tabular}{lccc}
\hline & 2010 & 2011 & p value \\
\hline Patients & 119 & 257 & \\
Upper GI endoscopies & 6,533 & 5,625 & \\
Age, years & $66.9 \pm 14.9$ & $68.6 \pm 14.9$ & n.s. \\
Sex (male/female) & $79 / 40$ & $169 / 88$ & n.s. \\
Hemoglobin, g/dl & $9.3 \pm 2.8$ & $8.6 \pm 2.6$ & $<0.05$ \\
Blood transfusions & $48(40.3 \%)$ & $152(59.1 \%)$ & $<0.01$ \\
Transfusions per unit & $5.3 \pm 2.9$ & $6.3 \pm 3.9$ & n.s. $(0.08)$ \\
\hline
\end{tabular}

Figures represent numbers or mean \pm SD.

\section{Materials and Methods}

Seven major hospitals in Miyagi prefecture, which was stricken by the Great East Japan Earthquake, joined this study (fig. 1). The participating institutions were comprised of both hospitals of the area along the coast struck by the tsunami and inland hospitals, and each played a central role in the medical care of each district. Cases of hemorrhagic ulcers identified both during the 3 months after the earthquake (March 11th to June 11th, 2011) and during the same period of the previous year (March 11th to June 11th, 2010) as controls were listed in each participating hospital. In this analysis, a peptic ulcer was defined as a mucosal break at least $5 \mathrm{~mm}$ in diameter with visible depth. Hemorrhage without ulceration (e.g. hemorrhagic gastritis) was excluded. In judging the hemorrhagic status of ulcers, not only ulcers which were endoscopically confirmed to be actively bleeding, but also cases with endoscopic findings of an ulcer with a blood clot or exposed vessel associated with definite evidence of hematemesis and/or melena were defined as hemorrhagic ulcers. The patients with Mallory-Weiss syndrome alone were excluded from the list. In analyzing the data, cases with concurrent traumatic injury were excluded in order to remove the involvement of physical stress in the development of hemorrhagic ulcers after the earthquake. Carcinomatous ulcers were also excluded from the list.

One of the authors (T.K.) visited each hospital during the period from September 2011 to February 2012 and systematically reviewed all hospital records and databases of endoscopic imaging for each case of hemorrhagic ulcer. The collected data included information concerning the diagnosis of ulcers, patient's age and sex, the location and number of ulcers, whether the ulcer was complicated by bleeding, the laboratory data (including the value of serum hemoglobin) at the time of visiting the hospital, whether the patient needed blood transfusion and the amount of transfusion, choice of therapeutics (endoscopic hemostasis/surgical operation/conservative treatment) and the prognosis of the patient. Gastric ulcers were divided according to their occurrence in the upper, middle or lower third of the stomach. Similarly, duodenal ulcers were divided into bulb and 2 nd portion ulcers. In cases of multiple ulcers at the same time, the location of the biggest one was determined as the occurrence site. Endoscopic hemostasis included a local injection of absolute ethanol method, a local injection of HSE (hypertonic saline-epinephrine), the clip- ping of an exposed vessel, an argon plasma coagulation method, hemostatic forceps coagulation method and spraying of thrombin. Conservative treatment cases mainly used proton pump inhibitor (PPI), blood transfusion and an intravenous drip injection under non-per-oral circumstances. In the information regarding prognosis analysis, not only whether the patient was discharged or died, but also whether there was further bleeding (re-bleeding) or not during admission in the hospital was included.

\section{Statistics}

In the comparison of data from the years 2010 and 2011, data were expressed as mean (SD) and statistical analyses were performed using the unpaired t test for continuous variables, while data were expressed as actual numbers (\%) and statistical analyses were performed using $\chi^{2}$ test for categorical variables. This retrospective study was approved by the Tohoku University Hospital Ethics Committee (No. 2011-231).

\section{Results}

\section{Comparison of Incidence and Background of}

Hemorrhagic Ulcers before and after the Earthquake

A total of 257 patients with hemorrhagic ulcers were identified using upper GI endoscopy within the 3 months after the earthquake while a total of 119 patients were identified in the same period of 2010. Comparisons of characteristics between the years 2010 and 2011 in all cases are shown in table 1 . Because of the electric power failure and the instability of the supply of medical equipment, etc., the total number of upper GI endoscopy examinations in 2011 decreased by $14 \%$ as compared with the same period in 2010. Meanwhile, the number of ulcer patients increased 2.2 fold in 2011 as compared with 2010. The mean ages of the subjects were similarly high and the subjects were predominantly male both in 2010 and 2011, and there was no significant difference in age and gender between the $2 \mathrm{ob}-$ 


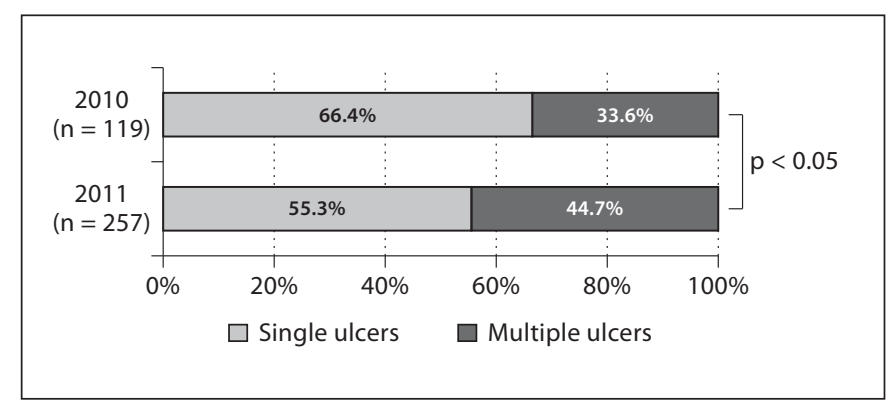

Fig. 2. Number of ulcers: comparison of the proportion of single ulcers versus multiple ulcers before and after the earthquake.

servation periods. In order to compare the proportions of elderly patients, we divided the patients into two age groups (below 65 and 66 years and over). However, there was no difference in the proportion of elderly patients between in 2010 and 2011 (56\% in 2010 vs. $62 \%$ in 2011).

In the 2011 cases, the values of serum hemoglobin at the time of visiting the hospital were significantly lower than those of the previous year $(9.3 \pm 2.8 \mathrm{~g} / \mathrm{dl}$ in $2010 \mathrm{vs}$. $8.6 \pm 2.6 \mathrm{~g} / \mathrm{dl}$ in $2011, \mathrm{p}<0.05)$. Consequently, the proportion of patients who needed blood transfusion in 2011 was significantly higher than in the previous year $(40.3 \%$ in 2010 vs. $59.1 \%$ in $2011, \mathrm{p}<0.01$ ). In addition, patients after the earthquake in 2011 tended to need more blood transfusions compared with those in 2010, although the difference did not reach statistical significance $(\mathrm{p}=0.08)$. These hemodynamic results suggest that the patients with hemorrhagic ulcer in the post-earthquake period had severer conditions than during the same period of the previous year.

\section{Characteristic Features of Post-Disaster Hemorrhagic}

Ulcers: Number of Ulcers and Occurrence Site

The ratio of single ulcer/multiple ulcers in the postearthquake period in 2011 and during the same period in 2010 are shown in figure 2 . The proportion of multiple ulcers in the post-earthquake period was significantly higher than in the previous year (33.6\% in 2010 vs. $44.7 \%$ in $2011, \mathrm{p}<0.05)$.

In figure 3 , it is clear that after the earthquake actual occurrences had increased in both gastric and duodenal ulcers. The number of patients with duodenal ulcers increased 1.58 fold in 2011 as compared with 2010, and more prominently, those with gastric ulcers increased 2.68 fold, from 71 in 2010 to 190 in 2011. In the comparison of the gastric ulcer/duodenal ulcer ratio, the proportion of gastric ulcers in the post-earthquake period was

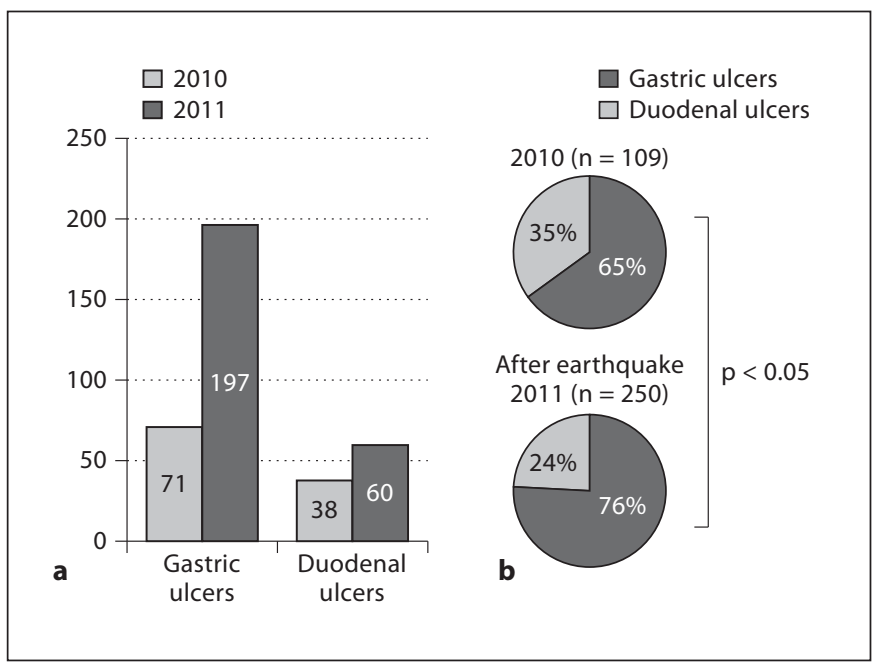

Fig. 3. a Number of gastric ulcers and duodenal ulcers. b Gastric ulcer/duodenal ulcer ratio. All hemorrhagic ulcers were divided into gastric or duodenal ulcers, concurrent gastric and duodenal ulcers were excluded for this analysis.

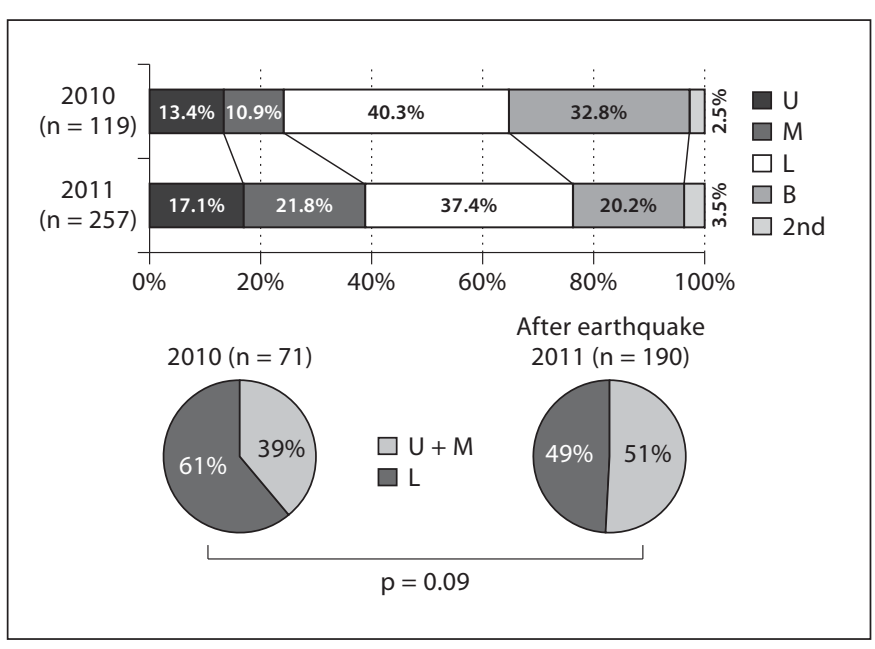

Fig. 4. Occurrence site of hemorrhagic ulcers. We divided all patients into five subgroups: gastric ulcers were divided into three subgroups [upper (U), middle (M) and lower stomach (L)], and duodenal ulcers were divided into 2 subgroups [bulbs (B) and after 2 nd portion (2nd)].

significantly higher than in the previous year $(65 \%$ in 2010 vs. $76 \%$ in $2011, \mathrm{p}<0.05)$. We divided all patients into five subgroups by the occurrence sites of the ulcers (fig. 4). Looking at this distribution, the proportion of gastric ulcers in the upper to middle stomach increased in 2011 compared with those in $2010(\mathrm{p}=0.09)$. 
Fig. 5. Treatment and prognosis: choice of treatment (endoscopic, surgical or conservative) and the patients' prognoses after the earthquake (data in bold) is compared with those from the same period in the previous year.

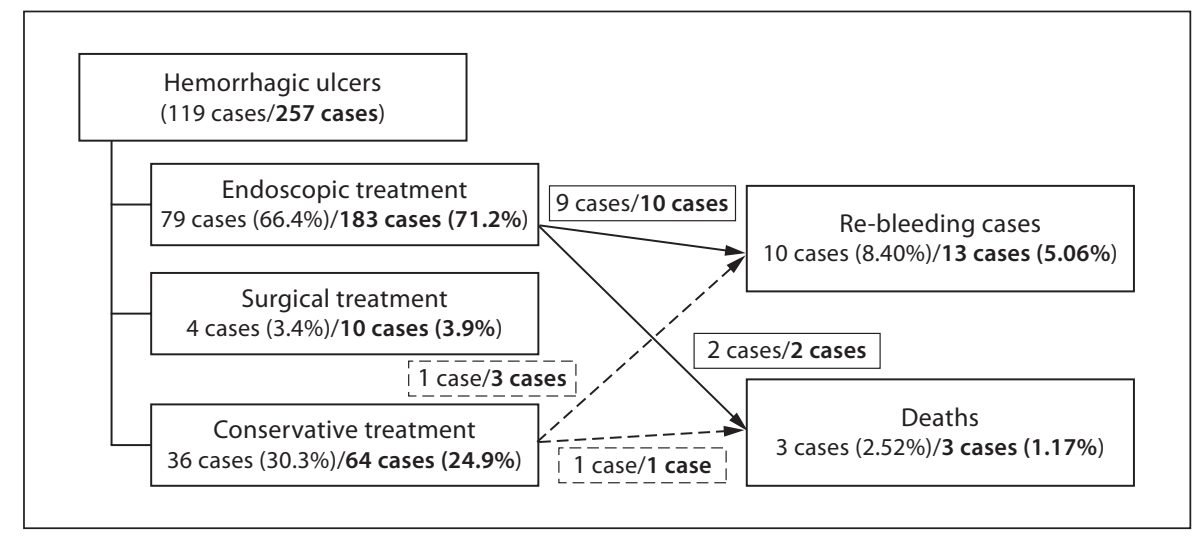

Choice of Treatment and the Prognosis of the Patient: Re-Bleeding Ratio and Mortality

We also investigated the choices of treatment for hemorrhagic ulcers and the subsequent prognoses of the patients. In figure 5, endoscopic treatment was selected most frequently both in 2010 (66\%) and the post-earthquake period of 2011 (71\%). The proportions of patients undergoing surgical treatment were nearly $3 \%$ in both 2010 and 2011. Consequently, the numbers of patients in the conservative treatment group in 2011 was rather decreased compared with the previous year (from 30\% in 2010 to $25 \%$ in 2011). Along with the more severe hemodynamic status in hemorrhagic ulcer patients in 2011, this result also suggests that patients in the post-earthquake period suffered severer conditions than in the previous year, because their conditions required aggressive hemostasis such as endoscopic treatment. Despite the dramatic increase in the number of hemorrhagic ulcers during the post-earthquake period, the proportion of rebleeding cases after the hemostasis treatment was rather lower in 2011 than in 2010 (5 vs. 8\%). In addition, in all re-bleeding cases, complete hemostasis was achieved by the subsequent endoscopic treatment not only in the rebleeding cases of 2010, but also those of 2011. As with the re-bleeding ratio, the mortality of patients with hemorrhagic ulcers in the post-earthquake period was rather lower than that in 2010 (2.5\% in 2010 vs. $1.2 \%$ in 2011 ). There were no fatalities due to hemorrhagic shock but there were 3 fatality cases both in 2010 and 2011 due to multiple organ failure after transient malperfusion for hypovolemia. These results suggest that hospitals in the area stricken by the Great East Japan Earthquake maintained a high level of treatment with high rates of resuscitation, as usual, but that hospitals were under severe circumstances because of the large-scale disaster.

\section{Discussion}

After the Great East Japan Earthquake we observed a dramatic increase in hemorrhagic ulcers in the areas most affected and found that the post-disaster hemorrhagic ulcers predominantly existed in the stomach, often in multiple. Since some small- or middle-scale hospitals in the stricken area were devastated and closed, emergency treatment after the earthquake was concentrated in the surviving major hospitals, leading to an apparent increase in the number of ulcer patients at participating hospitals after the earthquake. However, this scenario alone does not explain the compositional changes of ulceration after the earthquake, such as the gastric ulcer/ duodenal ulcer ratio or occurrence site of ulceration features. The dramatic increase of hemorrhagic ulcers after the earthquake could be ascribed to any factors related to the natural disaster (e.g. psychological stress), because it is unlikely that prevalence of the ordinary risk factors for the disease such as Helicobacter pylori infection or NSAID intake in the studied areas was substantially altered during the observation periods before and after the earthquake. In addition, endoscopic hemostasis therapy was mainly employed for treating those patients and the rebleeding ratio and mortality was kept as low as in the previous year, although the patients were in a severer clinical state than those examined in the previous year.

\section{Differences in the Features of Post-Disaster \\ Hemorrhagic Ulcers Compared to Those of \\ Conventionally Defined Stress Ulcers}

It is well known that characteristic ulcers are formed under specific environments such as post-surgery or after admission to intensive care units (ICU). In 1842, Curling [2] described 10 patients with duodenal ulceration occur- 
Table 2. Comparison of post-disaster ulcers in 2011 with conventional stress ulcers

\begin{tabular}{lllll}
\hline & ICU ulcers & Curling's ulcers & Cushing's ulcers & Post-disaster ulcers in 2011 \\
\hline Location & $\begin{array}{l}\text { Fundus/proximal } \\
\text { stomach }\end{array}$ & $\begin{array}{l}\text { Involving the antrum } \\
\text { Duodenum }\end{array}$ & $\begin{array}{l}\text { Duodenum } \\
\text { Stomach } \\
\text { Esophagus }\end{array}$ & $\begin{array}{l}\text { Stomach }>\text { duodenum* } \\
\text { Increased occurrence in } \\
\text { upper/middle stomach }\end{array}$ \\
\hline Number & Multiple & $\begin{array}{l}\text { Duodenal ulcers: tend } \\
\text { to be single }\end{array}$ & Much variety of appearance & Often multiple* \\
\hline $\begin{array}{l}\text { Trigger } \\
\text { and cause }\end{array}$ & $\begin{array}{l}\text { Admission to ICU for } \\
\text { critical illness }\end{array}$ & $\begin{array}{l}\text { Occurring after } \\
\text { extensive burns }\end{array}$ & $\begin{array}{l}\text { Trauma and surgery } \\
\text { Ulcers may be associated with } \\
\text { hypergastrine and acid hypersecretion }\end{array}$ & $\begin{array}{l}\text { Great East Japan } \\
\text { Earthquake and Tsunami }\end{array}$ \\
\hline
\end{tabular}

* Significant difference after earthquake in 2011 compared with 2010, as determined by $\chi^{2}$ test.

ring after extensive burns. Curling's ulcers more commonly involve the antrum and duodenum. Gastric ulcers are small, sharply demarcated and superficial. Duodenal ulcers tend to be single, deeper and more prone to perforate [2-5]. Ninety years after Curling's report, Cushing [6] identified trauma or surgery of the central nervous system as a stimulating trigger for a specific form of stress ulcer that bears his name. Cushing's ulcers, often deep, are found in the duodenum, stomach or esophagus. They are associated with hypergastrinemia and acid hypersecretion, which may account for the different distribution and appearance of Cushing's ulcers, as well as their increased tendency for bleeding [6-9]. In ICU ulcer cases, time-dependent changes of the mucosa found by endoscopy have been reported. Endoscopic examination of patients within $24 \mathrm{~h}$ of the provoking insult has revealed a patchy, ischemic pallor and the reddening of hyperemia coexisting in the proximal stomach [3, 10-13]. Endoscopy shows extensive, erosive changes of the fundus in most patients within $48 \mathrm{~h}$ of admission to an ICU. Subsequently, such lesions become somewhat deepened and more extensive and hemorrhagic. Even when bleeding develops, the lesions remain multiple, largely fundal and superficial $[10,14]$.

Compared with these conventionally defined stress ulcers caused by physical stress, our results were mainly seen as a reflection of psychological stress after the gigantic earthquake because physically injured cases were excluded from the present study. In this study, we clarified, for the first time, the detailed morphological characteristics of hemorrhagic ulcers after a large-scale disaster. First, the hemorrhagic ulcers more frequently occurred in the stomach than the duodenum after the earthquake, consistent with a previous report on another great earth- quake in Japan in 1995 [1]. Furthermore, in cases of gastric ulcers, the lesions tended to occur in the proximal portion of the stomach. Secondly, they often appeared as multiple forms of ulcers. As seen in the comparison in table 2, post-disaster hemorrhagic ulcers are more like ICU ulcers than Curling's ulcer or Cushing's ulcers. Hence, it is possible to assume the same etiological pathway existed between post-disaster ulcers and ICU ulcers. In this regard, further research is warranted on the etiological similarities between post-disaster and ICU ulcers.

\section{Suppression of Mortality from Hemorrhagic Ulcers} after the Earthquake

García-Iglesias et al. [15] reported in a meta-analysis that the hemoglobin value and the need for transfusion are associated with re-bleeding after endoscopic treatment for hemorrhagic ulcers. In addition, Rockall et al. [16] reported that the re-bleeding was associated with high mortality after acute upper GI hemorrhage. Meanwhile, in our study, patients showed lower hemoglobin values after the earthquake and a higher proportion of the patients needed blood transfusion compared with those examined in the previous year. These findings suggest that the hemorrhagic ulcer patients examined after the earthquake were in a severer clinical condition than those seen in the previous year. Multiple ulcerations caused by the stressful situation of a large-scale disaster or the limited accessibility to the hospital because of disrupted transportation networks could be responsible for the severe hemorrhagic manifestations after the earthquake. Nevertheless, in spite of the severe condition of the patients and poor availability of medical equipment after the earthquake, both the re-bleeding ratio $(8.4 \%$ in 2010 , $5.0 \%$ in 2011$)$ and the mortality $(2.5 \%$ in $2010,1.2 \%$ in 
2011) from hemorrhagic ulcers after the earthquake were similar or even lower than in the patients seen the previous year. Of note, of 183 hemorrhagic ulcer patients who received endoscopic treatment after the earthquake, only 10 cases required additional treatment for re-bleeding. Moreover, sufficient hemostasis was achieved for all rebleeding cases by the secondary endoscopic therapy. These results indicate that the endoscopic hemostasis therapy had been sufficiently effective even under the devastating conditions after the earthquake, which is in agreement with the previous reports regarding the efficacy of endoscopic hemostasis for hemorrhagic ulcers in an ordinary emergency medical service $[17,18]$.

Additionally, as PPI were administered in all cases in this study, the widespread usage of such potent acid-suppressing drugs probably contributed to the overall satisfactory outcomes to some extent, since a recent metaanalysis showed that prophylactic PPI administration is efficient in decreasing the incidence of GI bleeding in or- dinary emergency units [19]. In particular, in 64 patients there was only one fatality in a case that received conservative treatment after the earthquake, which suggests the efficacy of PPI monotherapy for hemorrhagic ulcers.

The Great East Japan Earthquake and Tsunami was responsible for many disaster victims and many patients with hemorrhagic ulcers. However, because of the high success rate of endoscopic hemostasis and, probably, the wide-spread usage of PPI, the therapeutic outcomes for hemorrhagic ulcers were satisfactory even after the earthquake. Our study provides important information that could be useful during and following large-scale disasters which may occur anywhere.

\section{Disclosure Statement}

The authors have no conflicts of interest to declare.

\section{References}

-1 Aoyama N, Kinoshita Y, Fujimoto S, Himeno S, Todo A, Kasuga M, Chiba T: Peptic ulcers after the Hanshin-Awaji earthquake: increased incidence of bleeding gastric ulcers. Am J Gastroenterol 1998;93:311-316.

$>2$ Curling TB: On acute ulceration of the duodenum in cases of burns. Med Surg Trans (Lond) 1842;25:260.

$\checkmark 3$ Czaja AJ, McAlhany JC, Pruitt BA Jr: Acute gastroduodenal disease after thermal injury: an endoscopic evaluation of incidence and natural history. N Engl J Med 1974;291:925929.

4 Czaja AJ, McAlhany JC, Pruitt BA Jr: Pathogenesis of acute duodenal disease after burns: role and acid secretion. Gastroenterology 1975;68:1023.

$>5$ Pruitt BA Jr, Goodwin CW Jr: Stress ulcer disease in the burned patient. World J Surg 1981;5:209-222.

6 Cushing H: Peptic ulcers and the interbrain. Surgical Gynecol Obstet 1932;55:1.

$>7$ Gordon MJ, Skillman JJ, Zervas NT, Silen W: Divergent nature of gastric mucosal permeability and gastric acid secretion in sick patients with general surgical and neurosurgical disease. Ann Surg 1973;178:285-294.
$>8$ Bowen JC, Fleming WH, Thompson JC: Increased gastrin release following penetrating central nervous system injury. Surgery 1974; 75:720-724.

$\checkmark 9$ Kamada T, Fusamoto H, Kawano S, Noguchi M, Hiramatsu K: Gastrointestinal bleeding following head injury: a clinical study of 433 cases. J Trauma 1977;17:44-47.

10 Lucas CE, Sugawa C, Riddle J, Rector F, Rosenberg B, Walt AJ: Natural history and surgical dilemma of 'stress' gastric bleeding. Arch Surg 1971;102:266-273.

11 Lucas CE, Sugawa C, Friend W, Walt AJ: Therapeutic implications of disturbed gastric physiology in patients with stress ulcerations. Am J Surg 1972;123:25-34.

12 Munakata A, Aisawa T, Yoshida Y, Tanaka S: Prospective study of acute gastric mucosal lesion (AGML) in patients receiving open heart surgery under extra-corporeal circulation. Gastrointest Endosc 1987;33:151.

13 Brown TH, Davidson PF, Larson GM: Acute gastritis occurring within 24 hours of severe head injury. Gastrointest Endosc 1989;35: 37-40.

14 Skillman JJ, Bushnell LS, Goldman H, Silen W: Respiratory failure, hypotension, sepsis, and jaundice. A clinical syndrome associated with lethal hemorrhage from acute stress ulceration of the stomach. Am J Surg 1969; $117: 523-530$
-15 García-Iglesias P, Villoria A, Suarez D, Brullet E, Gallach M, Feu F, Gisbert JP, Barkun A, Calvet X: Meta-analysis: predictors of rebleeding after endoscopic treatment for bleeding peptic ulcer. Aliment Pharmacol Ther 2011;34:888-900.

16 Rockall TA, Logan RF, Devlin HB, Northfield TC: Risk assessment after acute upper gastrointestinal haemorrhage. Gut 1997;41: 606-611.

17 Levin DA, Watermeyer GA, Deetleefs E, Metz DC, Thomson SR: The efficacy of endoscopic therapy in bleeding peptic ulcer patients. S Afr Med J 2012;102:290-293.

-18 Hearnshaw SA, Logan RF, Lowe D, Travis SP, Murphy MF, Palmer KR: Acute upper gastrointestinal bleeding in the UK: patient characteristics, diagnoses and outcomes in the 2007 UK audit. Gut 2011;60:1327-1335.

19 Barkun AN, Bardou M, Pham CQ, Martel M: Proton pump inhibitors vs. histamine 2 receptor antagonists for stress-related mucosal bleeding prophylaxis in critically ill patients: a meta-analysis. Am J Gastroenterol 2012; 107:507-520. 